\title{
Editorial
}

\section{Volume 48; Issue 1: Examining Art's Capacity to Challenge, Expand, and Deepen Connections within the Field of Art Education}

\author{
Adrienne Boulton, Kwantlen Polytechnic University \& University of British Columbia \\ adrienne.boulton@ubc.ca
}

Haley Toll, Memorial University of Newfoundland

hrmtoll@mun.ca

$\mathrm{T}$

This issue of the Canadian Review of Art Education/ Revue Canadienne de researches et enjeux en éducation artistique spotlights research practices in art education that connect to the ways that the arts may potentially challenge assumptions and normative thinking. Through these works, we are called to re-examine: the inherent nature of creativity; perceptions of the arts; STEM as housing disparate and incongruous interests as those of the arts; the value of artistic agency with adults with disabilities; ways for groups to connect with contemporary art exhibitions empathetically and poetically and the impact of a visual artist's residency within a Faculty of Education on students and faculty. This collection of diverse articles and book reviews in Volume 48 explore art and creative artmaking's capacity to disrupt and challenge preconceived notions, while also deepening cognitive and social connections. These skills and abilities are particularly important, and can be perceived as forms of resiliency, amongst the backdrop of navigating sudden and unexpected educational and policy changes (such as moving back and forth between virtual learning) during the COVID-19 pandemic while also collectively mourning oppressive colonial and racial injustices over the past year.

A common thread presents in each of these articles, which demonstrates the ways art and creative practices create spaces for empathetic connections between people from different cultures, deeper personal insights, sustainable practices, and holistic sensory-based learning. These are all important topics to underline and explore further in both research and practice-based literature, while significantly emphasizing more equitable, anti-colonial, social justice-based, and antioppressive practices in upcoming issues.

\section{Articles}

The first article of this section, written by Wiebe and Seaton, examines the parallels of design thinking processes with processes of creativity to articulate the ways in which design thinking fosters creative thinking in both design and art education. Their research explores students' application of the design thinking processes to external provocations. This work explores creativity as a teachable skill and looks to the value of staged learning and co-design in creativity.

Following Wiebe and Seaton's article, Forget's case study of four women working in fields related to art and science, examines how understandings of the convergence of common practices within these fields might disrupt the attrition rate of girls and women from STEM related fields by developing meaningful connections between and across these fields. 
Furthermore, Hochman and Esteves' research explored the impact of an inclusive learning collaboration within a university course designed and co-taught in a community-based arts organization that included adult individuals with disabilities as members. The study examined the university students' exploration of art fear and artistic agency through their work with the members.

As Head of Education at the PHI Foundation for Contemporary Art, Lemaire presents a feminist and poetic-based research study that explores the capacity to connect deeply with contemporary art through poetry and the concepts of movement, including cognitive, affective, emotional, and physical movements. This method, collaboratively created by the author along with her education team, invites visiting groups to the gallery to experience the contemporary artwork exhibitions deeply and empathetically. The author explains this process through presenting her reflexive poetry of an artwork featured in The Land of Plenty exhibition that took place from 20182019 and analyzing this poetic response. Powerful images from this exhibition are featured in Lemaire's article, while one of the instillations featured in Lemaire' article, Nada Act 1 (Civic, 2016), is the featured cover image of this issue.

Finally, Shields, Percy, and Meer-Chassé examine the process and impact of an artist-inresidence program in Art Education at the University of Victoria where visual artist, Teresa Vander Meer-Chassé, member of the White River First Nation of Beaver Creek was selected as the inaugural artist-in-residence. Their research which examines ways the artist-in-residence enriched student and faculty learning in a Faculty of Education.

\section{Book Reviews}

In the book review section of this issue, writing from Bangladesh, Khuda, presents an extensive analysis of Hunter et al.'s (2018), Education, arts and sustainability: Emerging practice for a changing world. Explaining the relevance and importance of this text on an in international scale, Khuda summarizes that "The book successfully presents an array of issues at the intersections of education, arts and sustainability which are urgent and pertinent to our fastchanging world" (n.p.)

While this issue published in 2021 features practice and research-based articles, our upcoming special issue will focus on reflexive and artistic Salon-based articles. This special issue aspires to feature lyrical, poetic, film, and image-based artistic explorations of current art education issues and themes. We look forward to continuously receiving meaningful and evocative content from insightful Canadian and international authors within the art education field.

\section{Acknowledgments}

It is with a bittersweet sentiment that we say good luck and good-bye to Haley Toll, Managing Editor of CRAE. CRAE contributors, reviewers, and readers will have had the privilege to engage with Haley's collaborative, generative, and graceful work since 2017. Haley began working with then Editor-in-Chief, Heather McLeod, bringing her skill and perspective from her art therapy and editing background. Haley is very strong in many areas but in particular, she brought a familiarity with e-publishing and a professional and supportive disposition to working with authors through the editing process as well as supporting the Editorin-Chief. Both Heather and I have appreciated her independent initiative which is balanced by her ability to work with others. She will be greatly missed but we look forward to seeing Haley's continued accomplishments, including her growing family, her work as Editor-in-Chief of the Canadian Art Therapy Association Journal, and her $\mathrm{PhD}$ completion in Curriculum and 
Instruction from the Memorial University of Newfoundland and Labrador. Congratulations to Abena Omenaa Boachie, $\mathrm{PhD}$ Candidate in the Faculty of Education at Memorial

University, who is taking over as the Managing Editor in January, 2022.

Adrienne Boulton, Editor-in-Chief, Canadian Review of Art Education

Haley Toll, Managing Editor, Canadian Review of Art Education

\section{References}

Cibic, J. (2016). Nada : Act 1 [Installation and Video]. (Photograph: R. M.

Tremblay). Everything That You Desire and Nothing That You Fear, 2018-2019. Fondation PHI pour l'art contemporain.

Hunter, M. A., Aprill, A., Hill, A., \& Emery, S. (2018). Education, arts and sustainability: Emerging practice for a changing world. Springer. https://doi.org/10.1007/978-981-10-77104_4 